\title{
Chapter 7 \\ Life Skills Education for Urban Youth in Honduras and Guatemala: A Capability Analysis of the Sports-Based Job Training Program A Ganar
}

\author{
Erin Murphy-Graham
}

\begin{abstract}
Drawing upon an extensive case study of a sports-based, life skills job training program for at-risk youth in Honduras and Guatemala, this chapter examines how program participants described the process of building skills, and how, if at all, this skill-building led to greater well-being. Second, it asks, to what extent are these experiences of program participants aligned with theories of education within the capability approach? These questions are addressed through a qualitative case study that was embedded within an experimental design (a randomized control trial) that took place over 5 years in urban areas of Honduras and Guatemala. The analysis suggests that the combination of exposure to new ideas and information in the three phases of the A Ganar program, coupled with concrete opportunities to test out such ideas, enabled youth to experience changes in their attitudes and behaviors around work, around themselves, and to develop new relationships and friendships. Based on these empirical results, the chapter identifies several elements that might better inform life skills education research and practice in $\mathrm{s}$ in the future. These include: (1) conceptualizing life skills as preconditions of capabilities (some of which might be better classified as values); (2) conceptualizing life skills as both ends and means of interventions, and (3) giving more consideration to the conversion factors, meaning the ability to convert resources into functionings, that limit the robustness of capabilities that life skills programs develop.
\end{abstract}

Keywords Education · Job-training $\cdot$ Sport $\cdot$ Skills $\cdot$ Capability approach $\cdot$ Central America $\cdot$ Qualitative research

E. Murphy-Graham $(\bowtie)$

University of California, Berkeley, Berkeley, CA, USA

e-mail: emurphy@berkeley.edu 


\section{Introduction}

If life skills are, broadly defined, the ability to live life well, a clear conception of well-being must inform programming with youth. As explained by DeJaeghere and Murphy-Graham (Chap. 1, this volume), the Capability Approach (CA) is a theoretical framework about wellbeing, freedom, freedom to achieve wellbeing, and the public values that can play a role in this process (Robeyns, 2017). For scholars and practitioners who wish to engage with life skills education from an approach that is "concerned with transformative change for persons and societies," (DeJaeghere \& Walker, 2021, p. 775), what does the CA offer? Can a capability analysis of life skills education make a difference in practice by first examining "the unjust nature of social structures, economic institutions, or social norms" (Robeyns, 2017, p. 215) and crafting programs that are informed by such analysis?

This chapter examines these questions, and provides a capability analysis of a life skills education program. It presents findings from an in-depth qualitative case study of a sports-based, life skills job training program for at-risk youth in Honduras and Guatemala. " The program A Ganar, which means "to win" or "to earn" in Spanish, recruited youth in urban communities and provided nine months of lifeskills, technical/vocational training, and an internship. This chapter does not examine the overall effects of the program (which can be found in Duthie et al., 2018). Here, I examine how A Ganar participants described the process of building "skills" and how this description is aligned with a notion of the purpose of education from a capabilities perspective. Based on this empirical analysis, the chapter suggests that there are several elements that might advance knowledge regarding life skills education research and practice. These include: (1) conceptualizing some life skills, particularly values, as preconditions of capabilities; (2) conceptualizing life skills as both ends and means of interventions; and (3) giving more consideration to the conversion factors, or the ability to convert resources into functionings, that limit the enactment of capabilities developed by life skills programs.

\section{Theoretical Framework: Education from a Capability Perspective}

The Capability Approach provides an alternative to approaches to wellbeing that are focused on income or economic wealth. It asks the questions: what are people really able to do and what kind of people are they able to be? What they can do and be are referred to as their "capabilities," and what they are actually achieving is called their "functionings" (Robeyns, 2017). The overall approach can be thought of as an open and flexible multipurpose framework for thinking about issues related to wellbeing,

\footnotetext{
${ }^{1}$ Murphy-Graham was the lead qualitative researcher of a randomized control trial evaluation team (see Duthie et al., 2018).
} 
freedom, and social justice. It also provides a broad framework within which individuals from different disciplines or fields can elaborate a capability theory for a specific use (Robeyns, 2017).

There is a growing number of educational studies that conceptualize education with regard to justice, accounting for both intrinsic and extrinsic roles of education, as well as what individuals value for their wellbeing (DeJaeghere, 2018; DeJaeghere \& Lee, 2011; DeJaeghere \& Walker, 2021; Peppin Vaughan, 2015; Peppin Vaughan \& Walker, 2012; Saito, 2003; Tikly \& Barrett, 2011; Walker, 2012). Scholars writing about education from a capability perspective have provided a rich set of ideas regarding the type of education we might aspire to, and have critiqued education commonly found around the world, including life skills education (DeJaeghere et al., 2016; Saito, 2003; Tikly \& Barrett, 2011; Peppin Vaughan, 2015; Peppin Vaughan \& Walker, 2012; Walker, 2012). As Walker and Unterhalter (2007, p. 15) explain, to count as education, processes and outcomes must enhance well-being by making one's life "richer with opportunity of reflective choice" and by enhancing the ability of people to help themselves and influence the world. Rather than a "bag of virtues" approach to education that lacks a clear theoretical rationale for defining objectives that can withstand philosophical criticism and that are at odds with research findings (Kohlberg \& Mayer, 1972), the capability approach allows education to expand students' capabilities to form goals and values rooted in social justice (Peppin Vaughan \& Walker, 2012, p. 497). The capabilities gained through educational interventions, including life skills and job training programs, should not be understood only in terms of specific skills and academic outcomes (which are indeed important), but also in terms of the values that are cultivated through the educational process.

Skills, or the ability, coming from one's knowledge, practice, and aptitude to do something well, might be considered the necessary elements of a capability, or a precondition for a capability. This implies that life skills, or the skills that help a person through everyday tasks and to be active and productive members of a community, must be coupled with favorable external conditions and circumstances. Stated more simply with a domain-specific example: one might have job skills, but to convert these skills into a functioning (paid work), the environment must have employment opportunities. Thus, the skills alone are not enough: they must be paired with real opportunities for individuals to do something with these skills.

This idea (conversion of skills into practice) is important for the capability approach, also called "conversion factors," which refer to the "different abilities that individuals have to convert resources into functionings" (Robeyns, 2017, p. 45). There are three types of conversion factors: (a) personal factors, such as sex, intelligence, physical condition, disabilities, etc., (b) social factors, such as social norms, societal hierarchies, power relations, etc., and (c) environmental factors, such as the environment in which a person lives, infrastructure, resources available, etc. When conceptualizing how a "skill" begets a capability (what a person can do) and a functioning (what they actually do), a key insight is that people have different abilities to convert resources into functionings (Robeyns, 2017). A capability approach, and its application to life skills education, acknowledges the structural constraints that 
exert a great deal of influence on individuals' conversion factors and capability sets (particularly when examining labor market and health outcomes).

The recognition of structural constraints may also help explain why interventions for youth are often deemed ineffective or have mixed results, as explained in Murphy-Graham and Cohen (Chap. 2, this volume), in the empirical review of studies focusing on labor market outcomes (see also Heckman \& Kautz, 2013). However, this raises one final point, which is that the measures used to determine effectiveness of life skills interventions might require additional refinement. This is related to the distinction of "means and ends:" Are life skills valuable because they are means to being employed, or might certain elements of life skills be important ends in themselves? As Robeyns points out, "there are some very important ends that do not depend very much on material means...For example, self-respect, supportive relationships in school or in the workplace, or friendship are all very important ends that people may want" (2017, p. 49). I explore these questions further through an empirical case study of youth in Honduras and Guatemala.

\section{Research Context: A Ganar in Guatemala and Honduras}

Young people in Honduras and Guatemala face a number of challenges, particularly if they are among the $59-66 \%{ }^{2}$ of the population that lives in poverty. Education, unfortunately, offers little hope for poor youth to escape poverty because there is limited coverage at the secondary level, low quality resulting in weak student learning, and low transition and graduation rates (Adelman \& Székely, 2016). Only a small percentage of poor youth gain the educational experiences they need to enter the formal labor market, and youth unemployment is twice as high as the total unemployment rate (International Labor Organization, 2021).

Implemented by Partners of the Americas (POA), a non-governmental organization based in Washington, D.C., the A Ganar program aims to address the serious problem of youth unemployment in Latin America and the Caribbean by utilizing soccer and other team sports to help at risk youth find positive ways to engage in their communities. A Ganar is a 7-9 month, three-phase job training program that combines sports-based field and classroom activities, vocational training, internships/apprenticeships, and various follow-on activities to help participants (1) find jobs, (2) start or expand their business, or (3) re-enter the formal education system. POA works with youth aged 17-24, and defines "at risk" as youth who have one or more of the following characteristics:

- Come from socially or economically-disadvantaged households or communities;

- Are school dropouts or are one or more years behind in school; or,

- Belong to communities plagued by high levels of drug use and/or trafficking, youth violence, and/or youth gangs. 
The program aims to help youth develop "life and employability skills" through sport-based activities, classroom training, and on-the-job experiences. Through this progression of activities, the program attempts to increase self-confidence and build trust between the youth and instructors, allowing for the reinforcement of key competencies. The specific life-skills that the A Ganar curriculum focuses on include: communication, teamwork, results, continual self-improvement, and discipline ${ }^{2}$ As Kwauk (Chap. 5, this volume) finds, sports-for-development interventions often emphasize the idea that important life skills can be transferred from the playing field to day-to-day realities - and like many of the programs she reviewed, A Ganar leans heavily toward a prosocial, self-improvement paradigm, particularly emphasizing teamwork and cooperative behavior.

The United States Agency for International Development (USAID) commissioned an impact evaluation (a randomized control trial) of A Ganar in Honduras and Guatemala. Key quantitative findings were:

- The program did not have any significant impact on employment rates, number of jobs, or hours worked in either country.

- A slight increase in job "quality" - particularly in wages, benefits, and job satisfaction - was detected in both countries. A Ganar youth in Honduras had significantly higher wages ( 2 more lempiras or $\sim \$ 0.10$ per hour, on average), marginally higher prevalence of benefits, and greater job satisfaction. A Ganar youth in Guatemala had $15 \%$ higher hourly wages and were $89 \%$ more likely to have a work contract.

- The program had a positive impact on some socio-emotional outcomes in both countries, including sense of positive identity, social competencies, commitment to learning, constructive use of time, and empowerment (see Duthie et al., 2018).

Here, I focus on findings from the qualitative case study that was embedded within the randomized control trial study.

\section{Methodology: Qualitative Case Study}

This qualitative case study was embedded within an experimental design (randomized control trial) of the A Ganar program. ${ }^{3}$ The entire study sample included approximately 3,000 youth who participated in A Ganar (we conducted interviews with a smaller qualitative subsample, described below). The study took place over 5 years, from 2012 to 2017, with cohorts of youth beginning and ending their

\footnotetext{
${ }^{2}$ These areas of emphasis are consistent with the social and emotional competencies area described in Murphy-Graham and Cohen (this volume). A Ganar also emphasizes the acquisition of information/knowledge through the technical training and internship phase - but the program does not have an emphasis on building critical thinking skills per se.

${ }^{3}$ The study was approved by Social Impact's Institutional Review Board (IRB) and consent was given by research participants at every stage of the process.
} 
participation in A Ganar at different times in each country (see Duthie et al., 2018 for a full description of the staggered nature of A Ganar implementation and research design and findings).

The qualitative study included data from a sub-sample of selected youth. I worked together with three Guatemalan and five Honduran research assistants to conduct a total of 362 in-depth qualitative interviews in Honduras and Guatemala. All interviews were conducted in Spanish. Our data collection involved two different types of interviews: (1) 24 "rich case studies" with youth at baseline, endline (after the program completed), and 18 months later; and (2) a larger sample of youth whom we interviewed at the program "exit" and "long term follow-up" - 18 months later. Rich case study interviews involved a purposive selection (see Maxwell, 2013) of 12 youth in each country (we wanted an equal representation of male and female youth, a range of age, and a range of educational backgrounds) that participated in the pilot phase of A Ganar implementation in each country. For each "rich case study", we also conducted interviews with a family member, a program facilitator, an internship supervisor, and if applicable, an employer. The purpose of these interviews was to gain a deep understanding of the overall context in which youth lived, their experiences in the A Ganar program, as well as the perspectives of those who came into contact with them throughout their participation in the program. Our early experiences with the rich case study interviews informed our decision to interview a greater number of participants when they completed the program, as well as during the long term-follow up; a larger sample would help us explain our quantitative findings and give us a greater sense of the range of experiences in the program.

For our larger sample, we interviewed a total of 208 youth (115 in Guatemala and 93 in Honduras) when they finished the program, and a total of 130 youth (86 in Guatemala and 44 in Honduras) 18 months after they finished the program. Both exit and long-term follow-up interviews prompted participants to reflect on their experiences in the A Ganar program, to name specific activities that they remembered from the various stages of the program (sports-based life skills training, technical training, internship), and to recount what had stayed with them from these activities. Every effort was made to not ask leading questions. All interviews were conducted in a private space (often a small office at a local youth organization) and recorded using digital recorders. All names used in this paper are pseudonyms.

\section{Data Analysis}

Digital recordings of interviews were transcribed and the transcripts were analyzed using Dedoose, a qualitative data analysis software analysis program. As a first stage of analysis, we drafted profiles of the rich case study youth. In these profiles, we drew upon interviews with the youth, their family members, their A Ganar facilitators, and internship supervisors. The rich case studies allowed us to identify salient themes to include in our subsequent interviews with the larger sample of youth. 
All interview coding was conducted by the author and a research assistant, using both inductive and deductive coding (Miles et al., 2014). A preliminary code list was developed from intended outcomes of the A Ganar program as well as from our insights from an initial read of interview transcripts. This code list was further refined as we coded the interviews and new themes emerged. The final code list had roughly 30 codes. Ten of these focused on context and background of youth's lives (for example, the difficulty of using public transportation due to frequent robberies), not program outcomes. One of the most frequently applied codes was "Impact of A Ganar" - this code also had seven different sub-codes that provided more specificity, including: academic benefits/school re-entry, employment, gender perceptions/ attitudes, life skills/employability features, self-esteem/confidence, social relations, and values.

After initial coding was completed, greater attention was given to the codes that were both most frequent and related to predefined program impacts. This attention allowed us to create a second-round coding system (Miles et al., 2014). Table 7.1 below lists our first and second round coding categories that focus on the impact of A Ganar:

Table 7.1 Codes and frequencies related to the impact of A Ganar used in qualitative analysis

\begin{tabular}{l|l}
\hline Code first round (frequency) & Code second round \\
\hline $\begin{array}{l}\text { Impact of A Ganar (parent code relating to } \\
\text { any mention of program impact) }\end{array}$ & \\
\hline Academic benefits, school re-entry (31) & $\begin{array}{l}\text { Re-enrollment in formal schooling } \\
\text { Enrollment in certificate or specified training } \\
\text { courses }\end{array}$ \\
\hline Employment (76) & Paid employment \\
\hline Altered gender perceptions/attitudes (16) & $\begin{array}{l}\text { Challenging gender norms } \\
\text { Difficult for women to work outside of home } \\
\text { Men must be breadwinners }\end{array}$ \\
\hline Employability (471) & $\begin{array}{l}\text { Work ethic: } \\
\text { Discipline } \\
\text { Respect }\end{array}$ \\
\hline Self-esteem/confidence (425) & $\begin{array}{l}\text { Feeling more confident generally } \\
\text { Feeling more confident about particular skills } \\
\text { (i.e. writing a cv, being interviewed) } \\
\text { Confidence provides enhanced sense of agency, } \\
\text { of being "unstuck" }\end{array}$ \\
\hline Social relations (754) & $\begin{array}{l}\text { Feeling less shy } \\
\text { Importance of play to foster relationships } \\
\text { Group as a team } \\
\text { New friends through the program } \\
\text { Getting along with others }\end{array}$ \\
\hline Values (271) & $\begin{array}{l}\text { Mentioning respect, discipline or punctuality as a } \\
\text { value }\end{array}$ \\
\hline &
\end{tabular}




\section{Findings}

The analysis of the interview data at all three stages of the study suggests that the combination of exposure to new ideas and information in three stages of the A Ganar program, coupled with concrete opportunities to test out such ideas, enabled youth to experience changes in their attitudes and behaviors around work, around themselves, and to develop new relationships and friendships. Figure 7.1 below summarizes the findings that have emerged from the data analysis and illustrates how what A Ganar calls "theory and practice" combined during each phase of the A Ganar program. The combination of theory, written lessons in the A Ganar workbook that introduce core ideas such as the importance of teamwork, and practice, when youth participate in the games/activities that are part of these lessons, allowed youth to change their attitudes, behaviors, and socialization patterns. We group these into three categories: preconditions of capabilities, capabilities, and functionings.

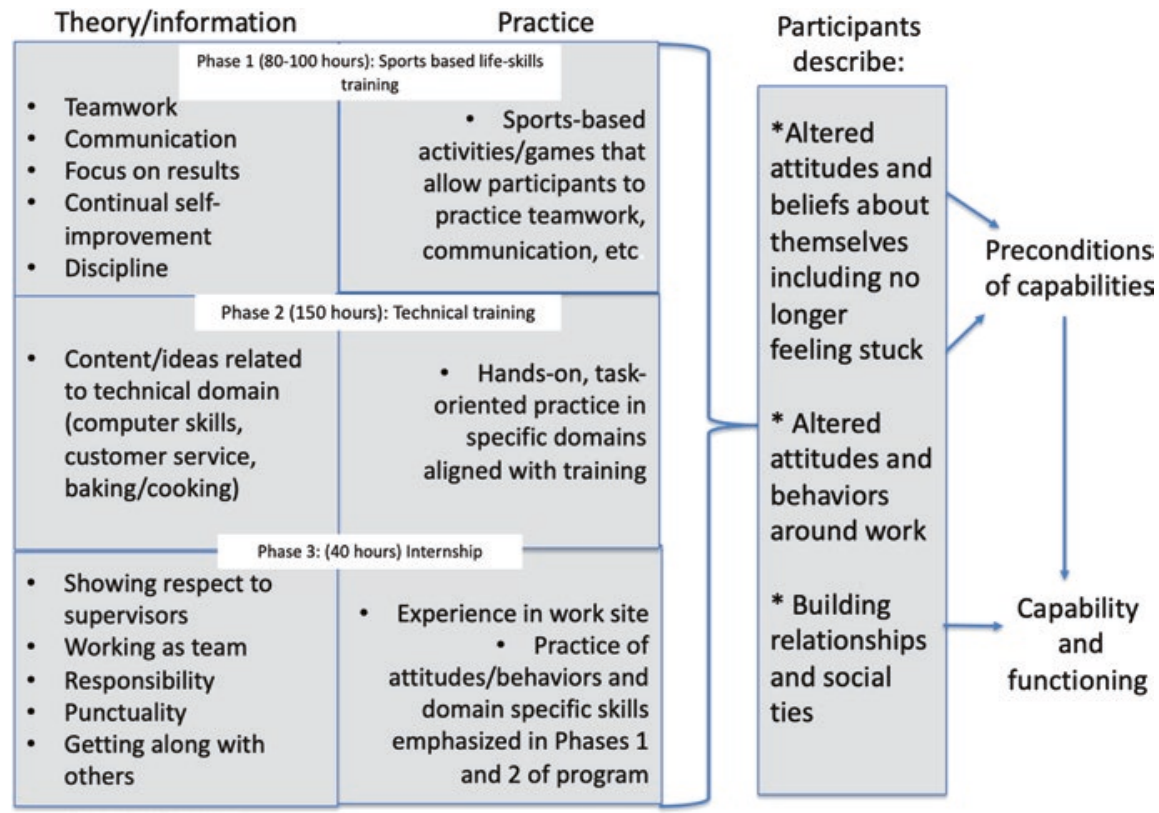

Fig. 7.1 Concept map representing participant experience in A Ganar. (Created by Author) 


\section{Preconditions of Capabilities: Altered Attitudes and Beliefs Including Not Feeling Stuck, Improved Self-Confidence, and Altered Work Ethic}

Youth described a number of preconditions that might allow them to accomplish the goals of A Ganar, and in particular, becoming employed or furthering their education. Exposure to the concepts regarding life skills and the practical experience that A Ganar offered allowed some youth to no longer feel "estancado/a" which translates to feeling stagnant, stuck, or bogged down. Youth explained that prior to their participation in the program they felt bogged down, that they did not have a future. As one program facilitator explained: "Emotionally, the youth come from a negative environment, with violence and without many opportunities. So being in the program, they see a light of, of hope one could say, knowing that, yes, one can have other things."

Excerpts from of our interviews with the participants Jimena and Madina capture how youth describe the ways in which A Ganar allowed them to feel differently about what each could accomplish:

Madina: It [the program] guided me a lot, it guided me so that I don't remain stagnant in only one place, in order to move forward, to give of myself, my hard work, and to give to other people because I'm not And with Jimena: the person that they imagined.

Interviewer: You told me that your plan was to study and work, right, do you believe that the program had any influence on this plan or not?

Jimena: $\quad$ Yes it had a lot to do with it, because first I said, "why would I study, for what reason would I study, I'm going to waste my time! But thanks to them now I have a different mentality. I want to study if only to set an example for my daughter that I can graduate and she can continue and do so.

Interviewer: And in what way do you think the program influenced you?

Jimena: In many things because they supported us, they told us and taught us to have our own goals, to have our own goals and to try to achieve them, to finish them.

Keiley, another youth we interviewed, used strikingly similar language in describing what she learned from her experience in A Ganar. She remarked, "they taught me to not be estancada [bogged down] and to move ahead." Likewise, a student named Rachel described a similar sentiment:

Well, that we have to continue moving forward no, not falter, and that the goals that we have in front of us we always have to achieve. To not remain stagnant...To persist, to persist because many times young people, sometimes because they don't have work, sometimes they don't have economic support, family support. So youth come to make decisions, it [A Ganar] helps them to take a different path. 
Here, Rachel hinted at negative decisions that youth can make, and that A Ganar provides an alternative. In addition to feeling an increased capacity to act in ways that would help youth seguir adelante, or get ahead in life, youth also mentioned trying to help others. In the case of Dugan, A Ganar helped him to stop hanging around with friends in a gang, and he said he became a "changed person."

One's mentality is not like, how should I say it... my mentality before, let's say that my mentality had been not to continue studying because I hung out with those gangs. Today my mentality is distinct and my mentality says I lost so much time with those gangs that I could have graduated... Now that I have entered the project I am now, how shall I say, a changed person. And I have the mentality to help others and involve them in the project in the new phase of A Ganar.

Youth frequently mentioned feeling more motivated to look for work or re-enroll in school due to their participation in the program. For many youth who we interviewed, low self-confidence was an underlying issue that prevented them from socializing with others and looking for work. However, their experience in A Ganar made them more confident. For example, Ramona explained:

Interviewer: What was important about what you learned?

Ramona: Important, I believe that it was the confidence in myself, something that I didn't have.

Improving self-confidence allowed youth to improve their ability to communicate with others. An anecdote that a youth named Jordana shared during her interview illustrates the interconnection of self-confidence and the ability to communicate. Jordana explained that she was very shy before entering the program. When asked to share something specific she learned in the program, she spoke without hesitation regarding a recent experience that illustrated her newfound confidence. Jordana completed her internship at Grupo Intur (a fast food conglomerate). Unlike many of her classmates who worked in the kitchens, she was placed in an office, doing human resources work. She enjoyed it very much, and felt that she had done a good job. When the internship ended, she had high hopes that she would be called back to continue working at Grupo Intur. At around the same time, Jordana became ill with a kidney infection. During her illness she indeed did get a call back from Grupo Intur, but she was unable to go to their offices because she was so sick. However, as soon as she felt better, she went to the office and explained what happened. She did not want them to think that she was irresponsible, and ultimately, she was rehired. She said that prior to her participation in A Ganar, she would not have known how to handle this situation. Jordana explained:

Jordana: So, how can I say it? Everything got complicated, so I couldn't go to work and as a result I had to leave my job. So that they did not see me as irresponsible I went to talk to them and they told me that when I was better and felt better that the doors were open. I think that this is also what I liked, I mean what I learned, I learned so so much from the project that this helped me to get the job.

Interviewer: uh huh, why exactly, why? 
Jordana: As I was saying I think because of the communication, because I was so timid, and to resolve this myself helped me earn the respect and affection of so many people at the company, which I now have.

Another youth, Gloria, said that before her participation in A Ganar her selfconfidence was so low that it physically hurt, "as far as, I don't know, it went as far as feeling pain in my body that my self-confidence was low, my self-confidence was so low." Now, she says that she feels much better about herself: "I am what I am!"

The emphasis on teamwork and communication in the first phase of the program, coupled with the practical activities that forced youth to practice these concepts, allowed youth to feel less shy and more self-confidence. For example, Yaron links his ability to no longer feel shy/ashamed with the new friendships that he has made in the program:

Well the experience that I have is that before I never spoke in public and... before I didn't get along with very many people because I felt ashamed to speak. I felt ashamed to speak in public. And now no, now I have a lot of friends and they taught me what respect is and why it is important.

Here we see how certain preconditions of capabilities, such as feeling more confident, can enable valued functionings, in this case having friends. Several participants, at all stages of the data collection, mentioned learning self-respect and respect for others as the foundation for being able to socialize with others and make new friends, described below.

In addition to describing improved self-confidence, participants in A Ganar described changed attitudes and behaviors around work, consistent with the themes presented in the curriculum and including the development of a more responsible and respectful work ethic, and increased discipline. Karina, for example, links many of these, and ultimately explains that they are important in the work environment as well as in the social sphere:

Karina: To work in a disciplined way, with respect, responsibility, we learned a lot because sometimes, how can I say it, sometimes we do things hastily. So now I speak in a more disciplined way. I learned how to be more responsible and to work more as a team, and more than that I learned control with other people

Interviewer: In what ways do you think that the program has helped you most in your life?

Karina: Well, discipline, I learned a lot. As I was saying before I used to do many things hastily and I learned that things shouldn't be done like that. They should be done in a way that is disciplined, with patience and to be responsible with things as well, not to do them in a way that is rushed.

Table 7.2 provides additional examples of how youth described altered attitudes and behaviors that they developed through A Ganar. These fall into the general categories of discipline, persistence, and responsibility. Together these might be considered the "work ethic" that A Ganar fostered among youth. 
Table 7.2 Examples of data regarding changed attitudes and behaviors in workplace

\begin{tabular}{l|l}
\hline Work ethic category: & Examples from interview excerpts: \\
$\begin{array}{l}\text { Discipline (arriving to work } \\
\text { on time, behaving and }\end{array}$ & $\begin{array}{l}\text { Interviewer: What of the aspects that you learned in the program } \\
\text { helped you the most when you completed your internship? } \\
\text { Elena: To pay attention and follow instructions. }\end{array}$ \\
& $\begin{array}{l}\text { Interviewer: Of the activities that you mentioned, which were } \\
\text { your favorite? } \\
\text { Caleb: Discipline } \\
\text { Interviewer: Why? } \\
\text { Caleb: Before I wasn't very disciplined. }\end{array}$ \\
\hline Persistence & $\begin{array}{l}\text { Edelio: Well on the court they taught us that one falls, if one falls } \\
\text { one can get up } \\
\text { Interviewer: What does that mean to you, that that you yourself } \\
\text { can get up? } \\
\text { Edelio: Look, there are people that want to see others fall. And } \\
\text { thanks to this course it taught me many things... } \\
\text { that for every time that one falls, one has to get up. } \\
\text { Candi: First of all I learned that a person has to keep moving } \\
\text { forward in life. }\end{array}$ \\
\hline $\begin{array}{l}\text { Rinty: In terms of my life it changed my life, it taught me to be } \\
\text { more responsible...it helped me a lot in terms of responsibility } \\
\text { and being punctual and it helped me to plan my time... } \\
\text { Interviewer: And what did you learn from the internship? What } \\
\text { did the internship teach you? } \\
\text { Ria: Well, well I learned to have much more responsibility. }\end{array}$ \\
\hline
\end{tabular}

Another component of the work ethic was to get along with co-workers even if they had difficult personalities. For example, Jimena mentioned that she learned how to get along with people with "different personalities."

Interviewer: Now if we talk a bit about other aspects that you learned in the program, which of these aspects that you learned during the program helped you most when you completed your internship? Of everything that you learned, what were you able to put into practice in your internship?

Jimena: Well the stuff about personality (carácter), that one is always going to work with people that have different personalities.

Interviewer: Okay.

Jimena: $\quad$ Perhaps one looked at them as friendly in the beginning and everything right?

Interviewer: Yes.

Jimena: But then later one has to see what their personalities are like, to not butt up against them... So to mold my personality with those of others...So more than anything this is what most helped me more than anything in the internship to interact with people, to socialize and all of that with the social part. 
Mateo's remarks reveal that the work ethic he developed through A Ganar's focus on teamwork, communication, and discipline, coupled with the technical skills he learned in the second phase, were all assets he brought to the work environment:

Mateo: It helped me a lot in terms of discipline, self-development. Because one looks to develop oneself... and the teamwork is fundamental, communication, respect, right, are things that the focus produces results. Which was the focus that I wanted to have in the internship. All of this helped me to concentrate on myself and to have a good attitude when carrying out my work. From there the technical part was very easy for me, because I as I was saying I had the necessary pillars to succeed, so what I learned here didn't produce a single problem. What's more it gave me a way of knowing how to develop myself even more.

This describes how certain preconditions, including discipline, self-development, and a "good attitude" enabled a valued functioning, being employed. For Mateo, these preconditions allow him to be something different - in his words to "develop" himself even more. This is very consistent with the notion of life skills as something that can allow people to improve their lives - to live life well.

\section{Capabilities and Functionings Through A Ganar Participation: Building Relationships and Social Ties}

One of the most consistent phrases uttered by participants in the in-depth interviews was teamwork (trabajo en equipo). Working as a team was one of the skills that youth described learning through sports activities, and this skill was linked closely with developing communication skills and learning to trust their peers. For example, Ileanna described learning to work as a team as one of the things she learned in the program:

Ileanna: The teamwork, because we played together, but we didn't communicate well. And there, values became important, communication. So in the moment of playing we made an agreement: "look let's play like this, you like this," this is how communication works in soccer.

When an A Ganar group starts, most of the youth do not already know each other. The games/activities are intended to "break the ice" and to allow the youth to socialize and to communicate. As Yolanda explained, during the first phase of the program, they "taught us to work in a team." She elaborated "thanks to sports and the instructors we were able to really connect with each other."

Yolanda: As I said in Phase 1 we did a lot of activities that required working in groups they taught us how to work in a team because when we first arrived we didn't know each other very much and there were tensions. But thanks to the sports and to the instructors we were able to connect with each other. We learned respect. We learned how to get along 
through the activities that we did. They put us together to play ball, we did some activities, we did some group games and it taught us how to work as a team. Because we had to listen, to listen to just one person and the others had to pay attention.

There are at least three reasons why making new friends is an important outcome for youth in the Honduran and Guatemalan context. First, many of these youth are socially isolated, particularly those that are no longer attending school. They lack a social group, and often they do not have contact with friends they used to go to school with. Second, they live in an environment characterized by violence and fear, and so making a new friend, particularly one that is not from their neighborhood, could have important implications in terms of improving social connections in these communities. Finally, for some youth, making new friends allows them to leave behind friends who engaged in risk behaviors (e.g. drinking, drug use, gang activity).

Making new friends was a consistent finding across the youth we interviewed (both male and female). Table 7.3 below summarizes a few of the youths' commentaries regarding their new friendships. One youth, Julian, even likened his new friends to an extended family. This extended social network is both a capability (to be able to have friends) and a functioning (being in a supportive social network). Therefore, in this outcome, we might think of A Ganar directly supporting the cultivation of the capability and functioning of what Nussbaum (2011) calls "affiliation", or "having the bases of self-respect and non-humiliation, to live with and towards others and show concern for other human beings..." (p. 34). This also echoes DeJaeghere's (Chap. 4, this volume) arguments about the importance of framing life skills from a relational approach - toward caring for others or reciprocity.

Table 7.3 Youth describe making new friends through A Ganar

\begin{tabular}{l|l}
\hline Alec & $\begin{array}{l}\text { And who knows with whom one is going to meet up, with bad company and all... But it } \\
\text { is helpful, because here [A Ganar] one learns what type of relationship to have. }\end{array}$ \\
\hline Ovidio & $\begin{array}{l}\text { Ovidio: Well finish my course and meet new people, make new friends. } \\
\text { Interviewer: Why? } \\
\text { Ovidio: Because in part it is good for me to meet new people, have new friends... We } \\
\text { cook, we play sports like soccer, we learned different games and we had good relations } \\
\text { between us as classmates. }\end{array}$ \\
\hline Katia & $\begin{array}{l}\text { With regards to sociability with others, with the other people I believe that it made me a } \\
\text { bit stronger in this aspect. In other words, to learn to make new friends, to learn to be } \\
\text { more sociable I think. I liked that a lot. }\end{array}$ \\
\hline Juan & $\begin{array}{l}\text { Meeting many friends, more than anything. Also it helped me get along better with my } \\
\text { classmates. }\end{array}$ \\
\hline Gaby & $\begin{array}{l}\text { Well because I got along with many, I made many friends and I got along with my } \\
\text { friends. }\end{array}$ \\
\hline Jerge & $\begin{array}{l}\text { Well some specific things were living together, like with my classmates. Because there } \\
\text { were classmates from many different places from here in Tegucigalpa. And, over time, } \\
\text { we became a big family. } \\
\text { with the whole team, so there was motivation. }\end{array}$ \\
\hline Lara & Well it involved learning a bit how to interact with classmates, to have friendships. \\
\hline
\end{tabular}


In summary, A Ganar youth frequently and consistently mentioned a variety of inter-related attitudes and behaviors that allowed them to learn to work as a team. The activities that were conducted during the first stage of the program served to allow them to establish close relationships with their peers, to overcome shyness, and to become more conscientious. They made new friends. Some who started the program quite shy, were able to learn how to communicate and treat their peers with respect. These skills allowed them to learn to work well with others and to get along with their peers and potentially their future co-workers. Jordana's remarks capture how all of these outcomes are related and mutually-supporting, with sports playing an important role:

What I liked most is that we learned respect, discipline, a lot of qualities like team work. We also went to the soccer field we also got over our shame. We made friends and after that we respected each other. And those of us who were ashamed to speak in public, I was one of them, are no longer. It no longer makes me embarrassed to get up in public and speak. This is how I have developed. The project taught me so much, and it is very beautiful!

\section{Structural Constraints of the Honduran and Guatemalan Contexts}

While participants expressed positive sentiments about their participation in A Ganar, many expressed frustration regarding the lack of formal work opportunities in Honduras and Guatemala. Again, the quantitative findings suggest that there was no impact of the program on employment. This points to the challenges of the labor market in their communities. As Cedric, one participant explained, "I think that here, opportunities are what we need more than anything. I think that there are a lot of people here like me, that have potential, but they get lost." Nancy also cited the national context as an impediment to finding work, although she also realized that part of the possibility of finding work is seeking out opportunities. She stated:

there are no opportunities, the ones that there are one has to give oneself, look for by oneself ...there are people that say I don't have any jobs, but jobs there are, to become somebody in a company one has to start from zero, and there are people who give with just one opportunity... I have learned that everything is one step at a time.

Again, while Nancy shows persistence in looking for work, she does so while acknowledging that there are few opportunities. Kyle, another youth interviewed, attributes his inability to find work to the problems in Honduras: "I believe that the situation is a bit complicated in this country."

In addition to the lack of formal employment opportunities, participants named a number of other issues that made things "complicated" in their countries. Crime and violence were consistently mentioned when youth discussed their neighborhoods. Cell phone theft was common on public buses, and youth discussed not wanting to work at night because of the danger of returning home in the dark. Some had papers stolen - for example Katherine had her work permit stolen when her 
home was robbed, and she was not able to replace it for many months. The everyday challenges of high crime and violence were a common theme in the lives of youth.

The participants acknowledge the many difficulties they faced when seeking employment, including stigma and gender discrimination. Youth mentioned, for example, that if they had a tattoo, employers assumed they were members of a gang. When employers heard where the youth lived, again they faced stigma because the neighborhoods are "rojo," or violent. Sex discrimination was also reported. For example, Evelyn, wanted to work in a kitchen, a space that in some restaurants is considered not appropriate for a woman:

I have tried in a few places, my sister-in-law works in Pollo Campero [a fried chicken fast food franchise], but she told me that they don't accept women in the kitchen, and my sister works at Lai Lai and they don't accept women there either.

Gender norms also made it difficult for women to work, as they were expected to care for young children. In Evelyn's case, even though A Ganar has influenced what she wanted to do and while she said she had not "lost faith in finding work" she acknowledged that "now with my daughter it is difficult."

The structural constraints of the Honduran context, including the availability of jobs, the high levels of crime and violence, stigma facing youth who live in certain neighborhoods, and gender discrimination, make their capabilities lack robustness. By "robust" I follow Robeyns who introduces robustness to refer to the probability of a capability being realized (2017, p. 98). Youth in Guatemala and Honduras have some opportunity to succeed in getting jobs, but their opportunities are less robust than other youth in Honduras who may be from less "complicated" (to use the words of one youth interviewed) communities.

\section{Discussion}

In our interviews with youth, they used language to describe program benefits that echoed terminology in the program curriculum, particularly the "life skills" of communication, teamwork, and discipline. As Fig. 7.1 illustrates, the combination of exposure to new information was combined with opportunities to practice, in games and activities, the ideas presented. The technical training and internship provided additional spaces for youth to practice concepts and behaviors that the program attempted to foster. These findings echo those of Honeyman et al. (Chap. 6, this volume) who also find that effective pedagogies for the development of what they term "soft skills" include those that are student-centered and that require active participation, problem-solving, and group work.

Applying a capability analysis to these findings, we consider the altered attitudes and beliefs participants described to be preconditions of capabilities. The stronger social ties that the program fostered are both capabilities and functionings because youth explained that they had both the real opportunity to be in friendships and they developed a stronger social network through their participation in the program. In other words, their attitudes were the precondition to being able to do and to be 
something - to socialize and live a life with close social ties. They are able to have more friends (a capability) because of their attitudes and values (the preconditions), and they actually do have friends who they socialize with (a functioning). These insights from the descriptive analysis of A Ganar, viewed through the lens of the capability approach, provide several important ideas for future programmatic and empirical work on life skills training programs, particularly for those who want to understand why, from a capabilities perspective, fostering educational opportunities for youth that help them develop life skills improves their well-being.

\section{What Counts as Success: Means and Ends of Life Skills Education}

Among all the youth we interviewed in Honduras and Guatemala, there was not a single account of an individual believing that the program was a negative experience. In fact, the interviewees described an overwhelmingly positive experience in the program. While some were frustrated that they still were not able to get jobs at the end of the program, they all believed it had a positive impact on their lives. The quantitative results support this qualitative finding, as the few statistically significant impacts of the program were in the overall social and emotional outcomes, including personal strength and positive identity (Duthie et al., 2018). However, for A Ganar and many other life skills programs, these are considered "secondary" outcomes - not of primary interest for donors and researchers.

A capability analysis can broaden the criteria by which program effectiveness is determined (see DeJaeghere et al., 2019, who make a similar argument in their analysis of a life skills program for youth in East Africa). Again, Robeyns argues that, "there are some very important ends that do not depend very much on material means...For example, self-respect, supportive relationships in school or in the workplace, or friendship are all very important ends that people may want" (2017, p. 49). DeJaeghere and Walker (2021) explain that from a capabilities approach, education has the potential to foster individual wellbeing through the formation of many aspects to their life quality - and our data suggest that the social ties were something that youth want, and view as a positive outcome of their participation. In Honduras and Guatemala violence and political instability have stagnated economic growth. It is unrealistic to expect that job-training programs will improve employment outcomes without accompanying macroeconomic shifts that create more employment opportunities for youth. Likewise, the violence that is prevalent in neighborhoods of Tegucigalpa, San Pedro Sula, and Guatemala City has made many youth afraid of leaving their homes, of socializing with new people, and of simply being in public spaces (Adams, 2012). Given the challenges of the context, programs that can improve youth wellbeing by fostering outcomes that youth value and want, given the challenges of their context, should be expanded - these may be more feasible goals than improving employment outcomes, particularly in the short term. While they are not tied to improved material status, they are an important component of youth wellbeing. These are important ultimate ends for life skills programming. 


\section{Values in Life Skills Programming}

In addition to fostering the capability to be in supportive social networks, A Ganar participants described changes in beliefs that included a sense that they were no longer "stuck," higher self-confidence, and attitudes that could be categorized as an improved work ethic. Again, these changed attitudes and beliefs can be thought of as "preconditions" of capabilities, or "internal characteristics" (Robeyns, 2017, p. 93). This finding highlights the importance of making explicit that values are part of the social and emotional competencies that life skills programs often attempt to foster. As Brush et al. (Chap. 3, this volume) explain, social and emotional learning is a process through which individuals learn and apply a set of related "nonacademic" skills - attitudes, behaviors, and values - to help direct their thoughts, feelings, and actions in ways that enable them to succeed in school, work, and life. For example, "discipline" and "responsibility" were common themes in our interviews with A Ganar participants, who considered these attitudes and values a key reason for their improved sense of wellbeing; they enabled actions that helped them in their personal and work lives.

One of the reasons why scholarship and programming in the field of "life skills" is so muddled (as mentioned Murphy-Graham \& Cohen, Chap. 2, this volume) is that skill is often used to describe both learned behaviors and values. We can develop greater habits of discipline and we also value being disciplined. Likewise, we can develop respect for others and we value this practice. Life skills programs, such as A Ganar, are attempting to cultivate a set of values around work: being disciplined, working hard, etc. Scholars writing from a capability perspective have made very helpful contributions regarding how to regard values and how these connect to life skills, namely, that certain values enable one to live life well. For example, Peppin Vaughn and Walker (2012) write that values are significant in shaping and influencing behavior and actions (in this sense we might consider them preconditions to capabilities). These values can be promoted "through meaningful educational activities; and that the educational opportunities provided in schools and colleges ought to foster behaviors and values which advance human development and well-being for individuals and society" (Peppin Vaughn \& Walker, 2012, p. 497).

As such, it might be clearer to be explicit that life skills programs are teaching values that have been deemed important for individual and social well-being that are related to individual identity and work ethic. At the same time, several authors (including Brush et al., Chap. 3, this volume; Peppin Vaughn \& Walker, 2012; Yitbarek et al., Chap. 11, this volume) have raised the question of whose values are present in life skills frameworks, and how do we ensure that these values do not reflect Western, Eurocentric frameworks? How do we ascertain that values reflect a commitment to equity and justice and an intolerance for discrimination and inequality, or in other words, that education is justice-enhancing (DeJaeghere \& Walker, 2021)? The Harvard Taxonomy Project classifies values as one of six domains of social and emotional learning, to "include understanding, caring about, and acting upon core ethical values; the desire to perform to one's highest potential; and the 
habits required to live and work together with others as a friend, family member, and citizen" (Brush et al., Chap. 3, this volume). A deeper engagement with the "core ethical values" and attitudes that life skills frameworks are informed by will be necessary to advance programming - particularly given Honeyman et al.'s finding that the non-academic skills and the "attitudes" aspect of curriculum development frameworks often end up neglected (Honeyman et al., Chap. 6, this volume).

A capabilities approach to life skills education suggests that values should not be imposed or transferred. They should not be taught through indoctrination, but rather, education should enable an individual to "learn, realize and clarify what is valuable to them; to form their own significant values" (Peppin Vaughn \& Walker, 2012, p. 508). This can happen through a kind of curriculum and pedagogy that creates spaces for values to be formed through activities, experiences, and exposure to knowledge. In the case of A Ganar, participants discussed learning these values through play, through the metaphor and practice of games and sports. They were exposed to the ideas, such as the importance of communication, in the A Ganar classes. In short, A Ganar seems to be an example of how education can expose while not indoctrinating - individuals to values, allowing them to be formed through activities and experiences.

\section{Conversion Factors Limit the Robustness of Capabilities}

While it is important to acknowledge that there is a set of explicit and implicit values that are often at the core of life skills programming, it is also important to recognize the ways in which the context may thwart putting these values into practice. This has been a major critique of "character education" programs in the United States. By shifting the focus onto "character" or "life" skills, these programs often fail to capture the context in which youth live. Programs emphasizing "character" or values often ignore the larger forces in society, such as the economic and social terrain, where these characteristics play out (Rose, 2014). As DeJaeghere and Walker (2021) explain, there is a mistaken belief that skills development and education will somehow solve defective labor markets.

A capability approach can take the structural constraints into consideration by engaging the concepts of conversion factors at individual, social, and environmental levels. For A Ganar youth, these included sex and gender-based norms and discrimination, the lack of safety, complications with transportation, and the larger economic context that made employment opportunities scarce. Without recognizing the conversion factors that may make individuals' capability sets less robust, life skills programming runs the risk of attempting a "quick fix" for a complicated problem. Boler and Aggleton (2004) argue that "if contexts are not taken seriously, educators risk speaking to a fictional world. In the hands of poorly prepared and hard-pressed teachers, life skills education appears to offer an instant one size fits all panacea, but complex problems require complex solutions" (p. 7). A more comprehensive model of how skills are mediated by conversion factors to ultimately lead to life-cycle 
outcomes is needed - hopefully future work will give greater attention to structural constraints.

\section{Conclusion}

This case study of A Ganar provides a capability analysis of life skills programs for youth. It clarifies a few points for scholars and practitioners that hope to better understand how skills might be conceptualized as part of programming for youth informed by a capabilities approach. Broadening our understanding of the outcomes that matter, as well as using concepts including preconditions, capabilities, and functionings, may prove useful when trying to understand the benefits and goals of life skills programming from a capabilities perspective. Finally, a careful analysis of conversion factors will provide a more realistic account of how life skills might lead to valued functionings for youth who live in such challenging contexts as urban Honduras and Guatemala.

\section{References}

Adams, T. M. (2012, August 6). Chronic violence and its reproduction: Perverse trends in social relations, citizenship, and democracy in Latin America. Wilson Center. https://www.wilsoncenter.org/publication/chronic-violence-and-its-reproduction-perverse-trends-social-relationscitizenship-and

Adelman, M., \& Székely, M. (2016). School dropout in Central America: An overview of trends, causes, consequences, and promising interventions. World Bank. http://documents.worldbank. org/curated/en/308171468198232128/pdf/WPS7561.pdf

Boler, T., \& Aggleton, P. (2004). Life skills based education for HIV prevention: A critical analysis. Paper prepared for the working group on HIV/AIDS. 17 May, 2004. Available at https:// healtheducationresources.unesco.org/sites/default/files/resources/life_skills_new_small_ version.pdf

DeJaeghere, J. (2016). Girls' educational aspirations and agency: The critical role of imagining alternative futures through schooling in a low-resourced Tanzanian community. Critical Studies in Education. https://doi.org/10.1080/17508487.2016.1188835

DeJaeghere, J. (2018) A capability approach to entrepreneurship skills: Social inclusion, community care and a moral economy. In McGrath, S \& Powell, L (Eds) The International Handbook of Education for the Changing World of Work. Springer Press.

DeJaeghere, J., \& Lee, S. K. (2011). What matters for marginalized girls and boys in Bangladesh: A capabilities approach for understanding educational well-being and empowerment. Research in Comparative and International Education, 6(1), 27-42.

DeJaeghere, J., \& Walker, M. (2021). The capabilities approach in comparative and international education: A justice-enhancing framework. In Jules T.D., Shields, R. \& Thomas, M. A (Eds) The Bloomsbury Handbook of Theory in Comparative and International Education. Bloomsbury Press. 
DeJaeghere, J., Wiger, N. P., \& Willemsen, L. W. (2016). Broadening educational outcomes: Social relations, skills development, and employability for youth. Comparative Education Review, 60(3), 457-479.

Duthie, M., Pucilowski, M., Anzoategui, L., Agpoon, B., \& Murphy-Graham, E. (2018). A Ganar alliance impact evaluation synthesis report Guatemala and Honduras. Social Impact. https:// pdf.usaid.gov/pdf_docs/PA00T78T.pdf

Heckman, J., \& Kautz, T. (2013). Fostering and measuring skills: Interventions that improve character and cognition (Working Paper 19656). National Bureau of Economic Research (NBER).

International Labor Organization. (2021). ILOSTAT Database. https://ilostat.ilo.org/data/

Kohlberg, L., \& Mayer, R. (1972). Development as the aim of education. Harvard Educational Review, 42(4), 449-496. https://doi.org/10.17763/haer.42.4.kj6q8743r3j00j60

Maxwell, J. A. (2013). Qualitative research design. Sage.

Miles, M. B., Huberman, A. M., \& Saldaña, J. (2014). Qualitative data analysis: A methods sourcebook. Sage.

Nussbaum, M. C. (2011). Creating capabilities: The human development approach. Harvard University Press.

Peppin Vaughan, R. (2015). Education, social justice, and school diversity: Insights from the capability approach. Journal of Human Development and Capabilities, 17(2), 206-224. https://doi. org/10.1080/19452829.2015.1076775

Peppin Vaughan, R., \& Walker, M. (2012). Capabilities, values and education policy. Journal of Human Development and Capabilities, 13(3), 495-512. https://doi.org/10.1080/1945282 9.2012.679648

Robeyns, I. (2017). Wellbeing, freedom and social justice: The capability approach re-examined. Open Book Publishing.

Rose, M. (2014, October 22). Character education: A cautionary note. Brookings Institution. https://www.brookings.edu/research/character-education-a-cautionary-note/

Saito, M. (2003). Amartya Sen's capability approach to education: A critical exploration. Journal of Philosophy of Education, 37(1), 17-33. https://doi.org/10.1111/1467-9752.3701002

Tikly, L. \& Barrett, A. (2011). Social justice capabilities and quality of education in low income countries. International Journal of Educational Development, 31(1), 3-14.

Walker, M. (2012). A capital or capabilities education narrative in a world of staggering inequalities? International Journal of Educational Development, 32(3), 384-393.

Walker, M., \& Unterhalter, E. (2007). Amartya Sen's capability approach and social justice in education. Palgrave MacMillan.

Open Access This chapter is licensed under the terms of the Creative Commons Attribution 4.0 International License (http://creativecommons.org/licenses/by/4.0/), which permits use, sharing, adaptation, distribution and reproduction in any medium or format, as long as you give appropriate credit to the original author(s) and the source, provide a link to the Creative Commons license and indicate if changes were made.

The images or other third party material in this chapter are included in the chapter's Creative Commons license, unless indicated otherwise in a credit line to the material. If material is not included in the chapter's Creative Commons license and your intended use is not permitted by statutory regulation or exceeds the permitted use, you will need to obtain permission directly from the copyright holder.

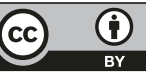

